\title{
SINGLE-DIODE AND TWO-DIODE PV CELL MODELING USING MATLAB FOR STUDYING Characteristics of SOlar CELl UNDER VARYING CONDITIONS
}

\author{
Vivek Tamrakar ${ }^{1}$, S.C. Gupta ${ }^{2}$ andYashwant Sawle ${ }^{3}$ \\ 1, 2, ${ }^{3}$ Department of Electrical Engineering, M.A.N.I.T. Bhopal, Madhya Pradesh, India
}

\begin{abstract}
This paper presents a detailed eplaination about various characteristics of ideal single diode, practical single diode and two diode equivalent circuit models realized for modeling of solar photovoltaic cell. Then it presents non-linear mathematical equations necessary for producing $I-V$ and $P$-V characteristics from a single diode model. A flowchart has been made for estimation of solar cell output current, for single diode and two diode model, using Newton-Raphson iterative technique which is then programmed in MATLAB script file accordingly. A typical $120 \mathrm{~W}$ polycrystalline solar module specifications have been used for model accuracy evaluation. The characteristic curves were obtained with the use of manufacturer's datasheet and it shows the precise correspondence to both the models.
\end{abstract}

\section{KEYWORDS}

Single Diode, Two Diode, I-V and P-V characteristics, solar irradiance, photovoltaic.

\section{INTRODUCTION}

A technology that directly converts free solar energy into electrical energy without causing any pollution to the environment is termed as photovoltaic power generation. The photovoltaic system consists of a group of solar cells connected in series and parallel. For simplicity in analyzing characteristics of solar cells, electrical equivalent circuits are realized and are hence modelled using simulation softwares. It helps in predicting behavior under various environmental conditions, and further in obtaining (I-V) and (P-V) characteristic curves.

The common approach is to utilize the electrical equivalent circuit, which is primarily based on a light generated current source connected in parallel to a p-n junction diode. Many models have been proposed for the simulation of a solar cell or for a complete photovoltaic (PV) system at various solar intensities and temperature conditions [1-4].

The key factor that affects the results of the simulation and accuracy in representating the nonlinear characteristics of the PV system is modeling [5]. There are different kinds of parametric models presented in various literatures in the past few decades, like single-diode model, twodiode model, three diode models, model with partial shading considerations and much more. The most commonly used models are single diode and two diode model, as they provide better relations with a practical solar cell keeping in mind the simplicity in implemtation and the 
iteration speed in the extracting parameters as well as I-V and P-V curves also gives minimum error with respect to characteristics of solar PV cell as per manufacturer`s datasheet.

In this paper a single diode also known as a five parameter model and a two diode model has been realized by formulating a flowchart with the help of schotkey equations, have been programmed in matlab using Newton-Raphson iteration method. In next section, different electrical equivalent circuits are discussed with their merits and demerits. In section III, the equaions necessary for calculating solar output current has been shown with flowchart. In section IV, both single diode and two diode models are implemented using matlab and respective curves are plotted. Then in section $\mathrm{V}$, results are discussed and then conclusion.

$\begin{array}{ll}I_{p h} & \text { Photocurrent }(\mathrm{A}) \\ I_{o} & \text { Diode saturation current }(\mathrm{A}) \\ q & \text { Electron charge, } 1.6021 \times 10^{-19} \mathrm{C} \\ k & \text { Boltzmann constant, } 1.3865 \times 10^{-23} \mathrm{~J} / \mathrm{K} \\ T & \text { Operating Temperature }(\text { Kelvin) } \\ n & \text { Diode factor }(1 \leq \mathrm{n} \leq 2) \\ \mathrm{G} & \text { Irradiance }\left(\mathrm{W} / \mathrm{m}^{2}\right) \\ R_{s} & \text { Series resistance }(\Omega) \\ R_{p} & \text { Shunt resistance }(\Omega) \\ n_{s} & \text { Number of cells in series } \\ V_{o c} & \text { Open circuit voltage } \\ I_{s c} & \text { Short circuit current } \\ V_{m p} & \text { Voltage at the maximal power point } \\ I_{m p} & \text { Current at the maximal power point } \\ I_{d} & \text { Current through the diode } \\ \mathrm{I} & \text { PV module current }(\mathrm{A}) \\ \mathrm{V} & \text { PV module voltage }(\mathrm{V}) \\ E_{g} & \text { Silicon gap energy of semiconductor } \\ v_{T} & \text { Thermal voltage equivalent }(\mathrm{V}) \\ \mathrm{STC} & \text { Standard temperature condition }\end{array}$

\section{Electrical Equivalent Circuits}

\subsection{Ideal Single Diode Model}

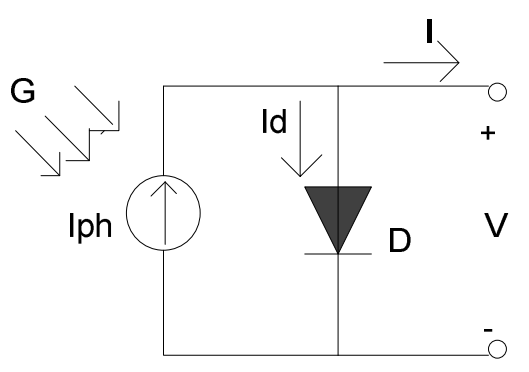

Figure 1. Ideal single diode model

This one is the most simplified form of an ideal PV cell through which the output voltage and current relations comes out to be, 
Electrical \& Computer Engineering: An International Journal (ECIJ) Volume 4, Number 2, June 2015

$$
\begin{aligned}
& I=I_{p h}-I_{d} \\
& I_{d}=I_{o}\left(e^{\frac{v}{n_{s} v_{T}}}-1\right) \\
& v_{T}=\frac{n k T}{q}
\end{aligned}
$$

But this model doesn`t give accurate I-V and P-V curve characteristics.

\subsection{Practical Single Diode Model}

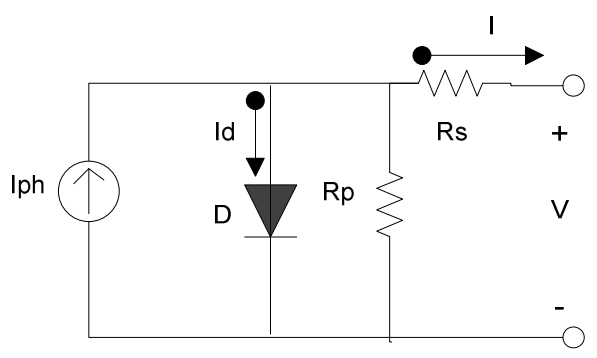

Figure 2. Practical single diode model

This one is an equivalent circuit of a practical PV cell. In many literatures it is also termed as a five parameter model $\left(I_{o}, n, R_{s}, R_{p}, I_{p h}\right)$. It takes into account different properties of solar cell as:

- $R_{S}$ is introduced as to consider the voltage drops and internal losses in due to flow of current.

- $R_{p}$ takes into account the leakage current to the ground when diode is in reverse biased.

- But this model has neglected recombination effect of diode, which is why it is still not the most accurate model.

$$
I=I_{p h}-I_{o}\left(e^{\frac{V+I R_{S}}{n_{s} v_{T}}}-1\right)-\frac{V+I R_{S}}{R_{p}}
$$

\subsection{Two Diode Model}

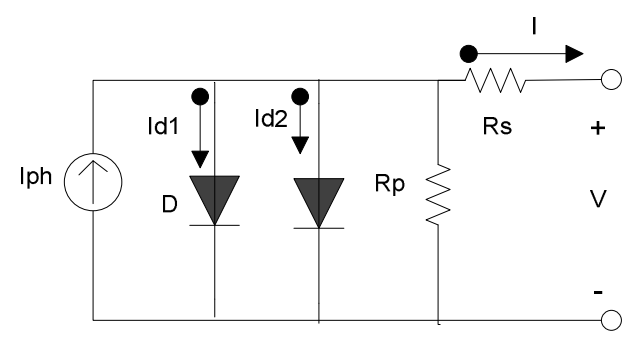

Figure 3. Two diode model

This is the modified form of single diode circuit which takes into account the effect of recombination by introducing another diode in parallel. 
Electrical \& Computer Engineering: An International Journal (ECIJ) Volume 4, Number 2, June 2015

$I=I_{p h}-I_{o 1}\left(e^{\frac{V+I R_{S}}{n_{S 1} v_{T}}}-1\right)-I_{o 2}\left(e^{\frac{V+I R_{S}}{n_{S 2} v_{T}}}-1\right)-\frac{V+I R_{S}}{R_{p}}$

But now there will be two unknown diode quality factors. Hence no. of equations and unknown parameters increases to two thereby making calculations little bit more complex.

At lower values of irradiance and low temperatures, two diode model gives much more accurate curve characteristics as compared to single diode model.

So taking all aspects into consideration, as far as mathematical computation and number of iterations are concerned, single diode model turns out to be fast results due to less complex equation and also computational errors are less unlike in case of two-diode model. But two diode model gives more sharp and accurate characteristics under varying weather conditions with longer iterations and parameter calculations.

\section{Mathematical Equations For Plotting I-V And P-V Curves}

As current through $R_{p}$ is very less compared to other currents, value of $R_{p}$ has been assumed to be negligible for sake of simplicity in calculation.

Now, photocurrent and reverse saturation current are temperature dependent parameters as,

$I_{p h}=\left(I_{p h}\right)_{T_{1}}+K_{o}\left(T-T_{1}\right)$

Where, $T_{1}$ is a normal standard temperature.

$\left(I_{p h}\right)_{T_{1}}=\left(I_{S C}\right)_{T_{1}} \frac{G}{G_{S T C}}$

$K_{o}=\frac{\left(I_{S c}\right) T_{2}-\left(I_{S C}\right) T_{1}}{T_{2}-T_{1}}$

The cell photocurrent is directly proportional to irradiance. Although cell performance does not degrade significantly but PV cell efficiency depends on incident solar energy.

$I_{o}=\left(I_{o}\right)_{T_{1}} \times\left(\frac{T}{T_{1}}\right)^{3 / n} \times e^{\frac{q(E g) T_{1}}{n k}\left(\frac{1}{T}-\frac{1}{T_{1}}\right)}$

$\left(I_{o}\right)_{T_{1}}=\frac{\left(I_{S c}\right)_{T_{1}}}{\left(e^{\frac{q\left(V_{o c}\right)_{T_{1}}}{n k T_{1}}-1}\right)}$

In case of two diode model, both diodes have different diode quality factors $\left(\mathrm{n}_{1} \& \mathrm{n}_{2}\right)$ hence, different reverse saturation currents as $\mathrm{I}_{\mathrm{O}_{1}} \& \mathrm{I}_{\mathrm{O}_{2}}$.

The value of series resistance can be estimated by,

$R_{S}=-\left(\frac{d V}{d I}\right)_{V_{o c}}-\frac{1}{X_{v}}$ 
Electrical \& Computer Engineering: An International Journal (ECIJ) Volume 4, Number 2, June 2015

$X_{v}=\left(I_{o}\right)_{T_{1}} \frac{q}{n k T_{1}} e^{\frac{q\left(V_{o c}\right) T_{1}}{n k T_{1}}}-\frac{1}{X_{v}}$

The flowchart for estimation of cell current with irradiance, temperature and cell voltage as input parameters is as shown in Fig. 4. The cell voltage must be a row vector whose range should cover all possible values PV cell is able to produce under specified conditions from manufacturers.

The ratio of the maximum power that can be delivered to the load and the product of $I_{S C}, V_{O C}$ is termed as fill factor. It is a measure of the real I-V characteristics. For value of 0.7 or higher are considered as good cells. FF increases with decrease in temperature.

$F F=\frac{P_{\max }}{V_{o c} I_{s c}}=\frac{V_{m p} I_{m p}}{V_{o c} I_{S c}}$

From I-V characteristics of PV cell, at extreme points, from (4), it changes to,

At open circuit condition,

$0=I_{p h}-I_{o}\left(e^{\frac{V_{o c}+I R_{S}}{n_{S} v_{T}}}-1\right)-\frac{V_{o c}+I R_{S}}{R_{p}}$

At short circuit condition,

$I_{s c}=I_{p h}-I_{o}\left(e^{\frac{I_{S c} R_{S}}{n_{s} v_{T}}}-1\right)-\frac{I_{S c} R_{S}}{R_{p}}$

At maximum power point condition,

$I_{m p}=I_{p h}-I_{o}\left(e^{\frac{V_{m p}+I_{m p} R_{S}}{n_{s} v_{T}}}-1\right)-\frac{V_{m p}+I_{m p} R_{S}}{R_{p}}$ 
Electrical \& Computer Engineering: An International Journal (ECIJ) Volume 4, Number 2, June 2015

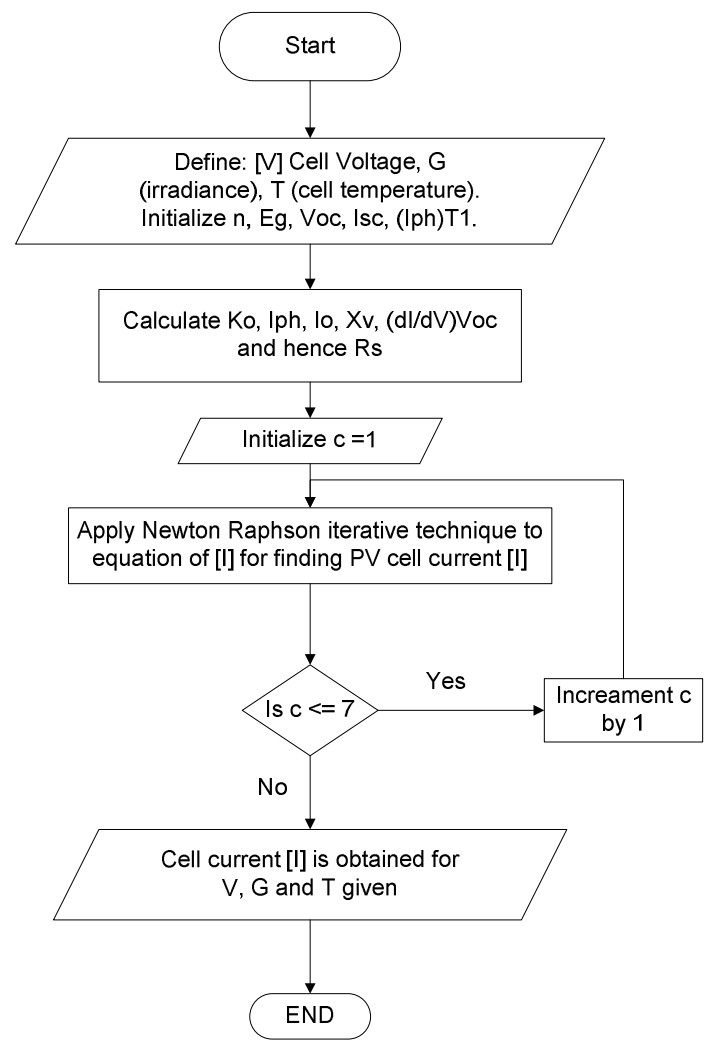

Figure 4. Flowchart for cell current calculation

\section{Modeling Of The PV Module}

The Specifications of BP Solarex MSX-120 polycrystalline PV module is chosen for modeling. It provides 120 Watt of nominal maximum power and consists of 36 series connected $\mathrm{Cr}$-Si type PV cells. Its specifications are shown in Table 1. By using matlab program the PV module was implemented using flowchart for both single diode and two diode equivalent circuit models. For simplicity, $R_{p}$ has been considered as infinite.

Table 1.

\begin{tabular}{|l|l|}
\hline \multicolumn{1}{|c|}{ Electrical Parameters } & BP MSX-120W \\
\hline Voltage Configurations & 12 or $24 \mathrm{~V}$ \\
\hline Nominal power rating $\left(\mathrm{P}_{\mathrm{m}}\right)$ & $120 \mathrm{~W}$ \\
\hline $\mathrm{V}_{\mathrm{mp}}$ & $17.1 \mathrm{~V}$ \\
\hline $\mathrm{I}_{\mathrm{mp}}$ & $7.0 \mathrm{~A}$ \\
\hline $\mathrm{I}_{\mathrm{sc}}$ & $7.6 \mathrm{~A}$ \\
\hline $\mathrm{V}_{\mathrm{oc}}$ & $21.3 \mathrm{~V}$ \\
\hline Number of cells in series & 36 \\
\hline Weight & $14.0 \mathrm{Kg}$ \\
\hline
\end{tabular}


The necessary parameters are evaluated and assumptions have been made during execution of equations listed in previous section. This program takes irradiance, cell temperature and PV module voltage as inputs and with the help of equations it returns output current value of PV module for all values of voltage vector so applied in the program.

\section{RESULTS AND DISCUSSIONS}

The plots of I-V characteristic curves have been produced by varying certain parameters one at a time keeping other parameters constant at STC. In matlab script file, flowchart specified in this paper is implemented.

Fig. 5.a and Fig. 5.b describes I-V characteristics of single diode and two diode model for varying solar irradiance value G (at STC is $1000 \mathrm{~W} / \mathrm{m}^{2}$ ) respectively. On observing the curve we see that with increase in irradiance values cell current value also increases proportionally but cell voltage increases very less. On observing both curves closely we see that I-V curve of two diode model Fig. 5.b is more steeper as compared to single diode Fig. 5.a.

Fig. 6.a and Fig. 6.b describes I-V characteristics of single diode and two diode model for varying temperature $\mathrm{T}$ respectively. It is observed that as temperature increases cell current also increases slightly and cell voltage shows significant decrease in its value. Here on observation we see that slope of two diode model I-V curve Fig. 6.b is more when compared with single diode curve Fig. 6.a.

Fig. 7.a and Fig. 7.b describes P-V characteristics of single diode and two diode model for varying solar irradiance value $G$ respectively. We can locate its peak i.e. maximum power point with respective voltages for varying irradiance and temperature respectively. And it is being observed that as irradiance increases output power also increases and reaches nominal power point at STC. Also, with increase in temperature, output power decreases. On observing P-V characteristics for both single diode and two diode models we figure out that maximum power occurs at slightly higher values of output voltage in case of single diode P-V curve Fig. 7.a with little bit higher maximum power as compared to two diode P-V curve Fig. 7.b.And when temperature is varied for $\mathrm{P}-\mathrm{V}$ characteristics Fig. 8.a and 8.b we find out that in case of two diode curve Fig. 8.b maximum power is more and it occurs at slightly higher value of output voltage as compared to single diode curve Fig. 8.a.

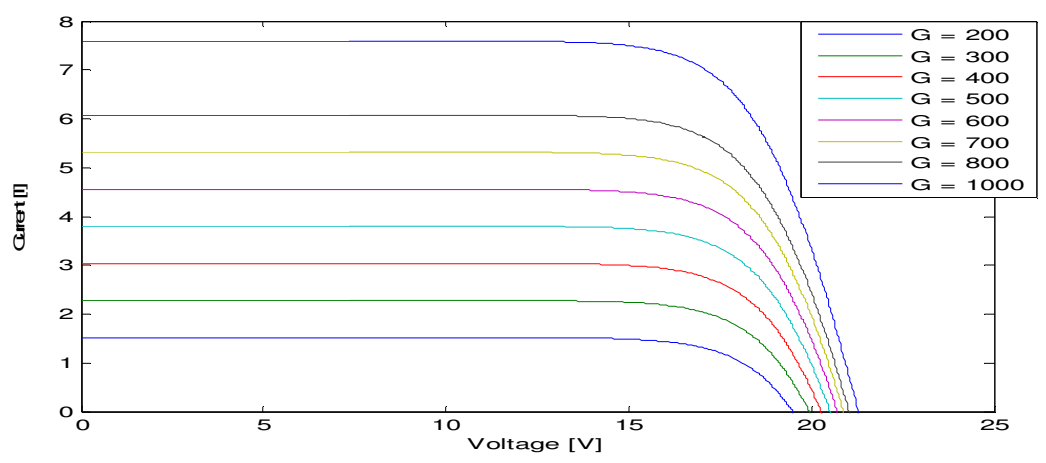

Figure 5.a I-V characteristics of single diode for varying irradiance $\mathrm{G}(\mathrm{W} / \mathrm{m} 2)$ 
Electrical \& Computer Engineering: An International Journal (ECIJ) Volume 4, Number 2, June 2015

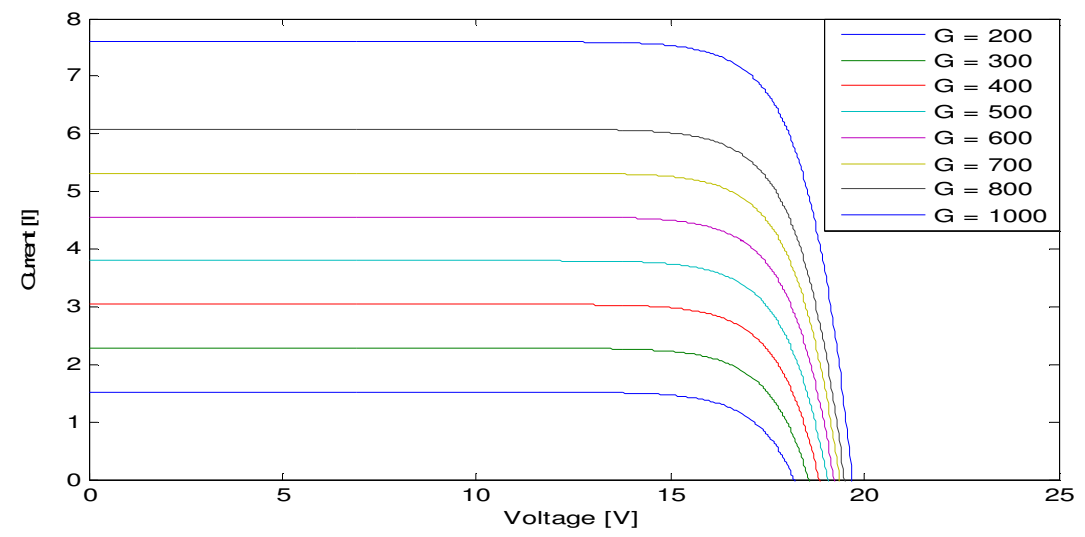

Figure 5.b I-V characteristics of two diode for varying Irradiance G (W/m2)

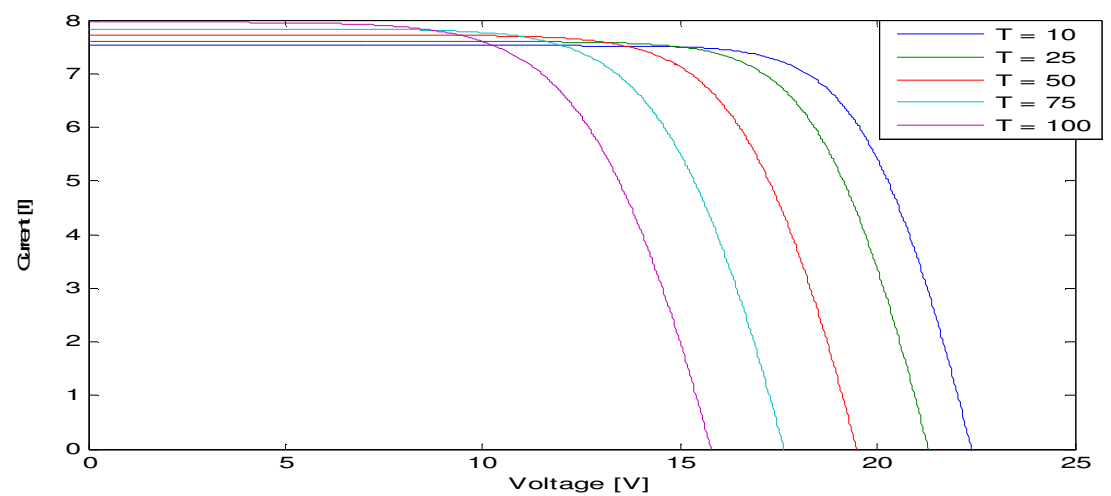

Figure 6.a. I-V characteristics of single diode for varying temperature $\mathrm{T}$ (C)

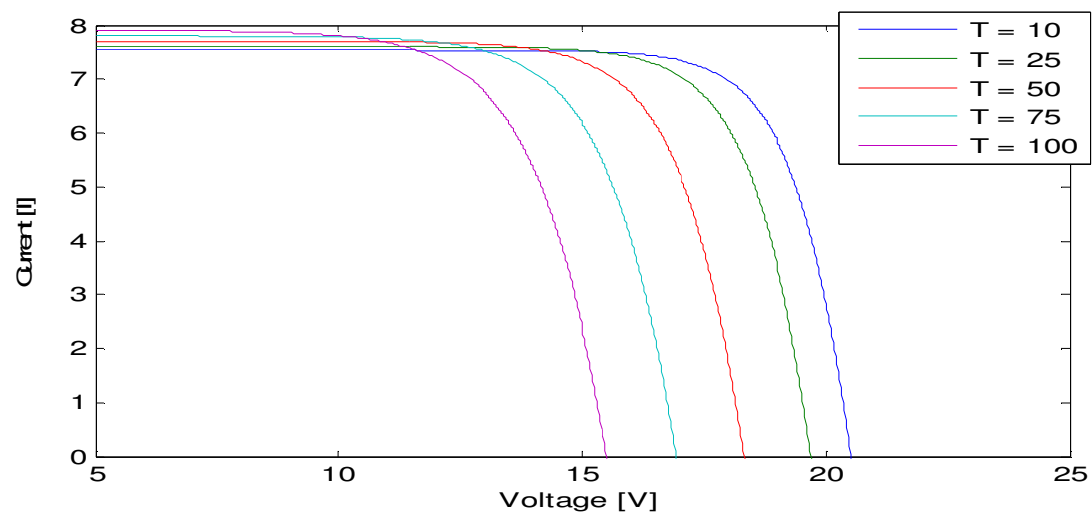

Figure 6.bI-V characteristics of two diode for varying temperature T (C) 
Electrical \& Computer Engineering: An International Journal (ECIJ) Volume 4, Number 2, June 2015

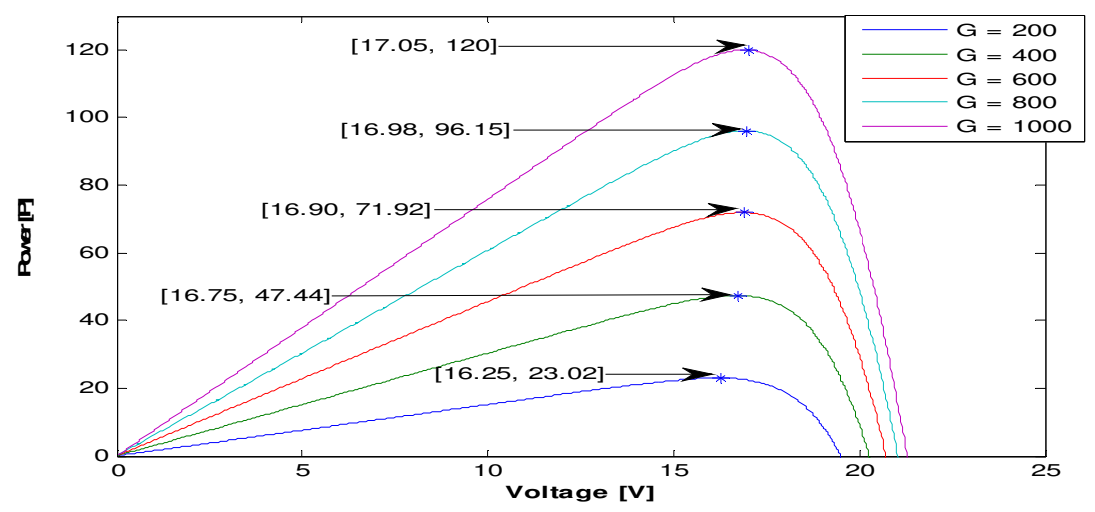

Figure 7.a P-V characteristics of single diode for varying irradiance $\mathrm{G}(\mathrm{W} / \mathrm{m} 2)$

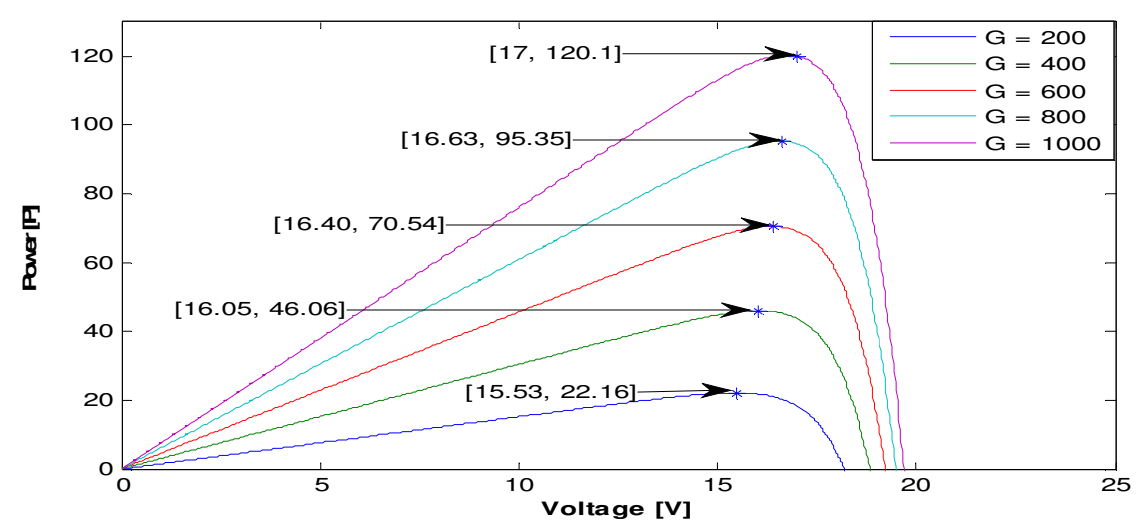

Figure 7.bP-V characteristics of two diode for varying irradiance G(W/m2)

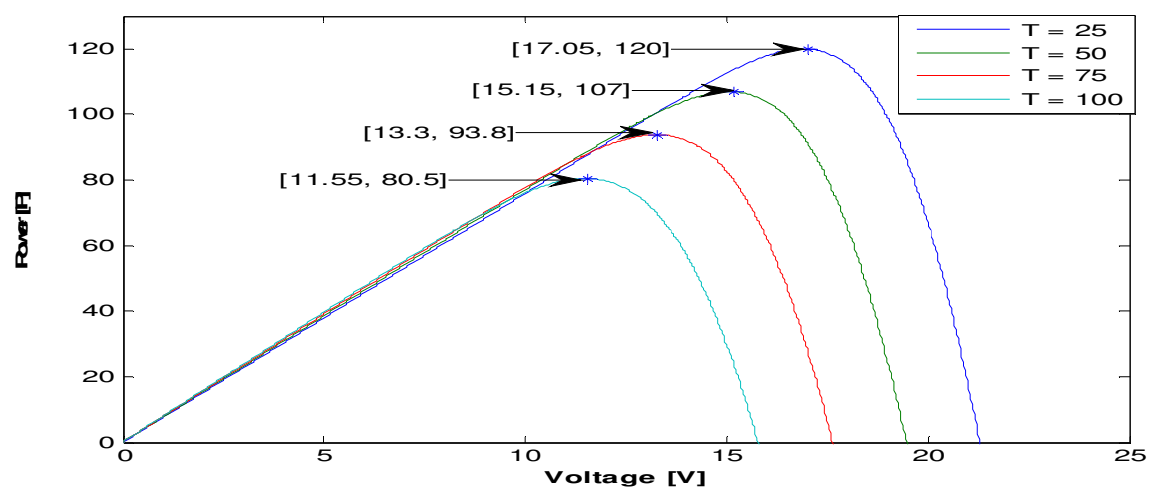

Figure 8.a P-V characteristics of single diode for varying temperature T (C) 


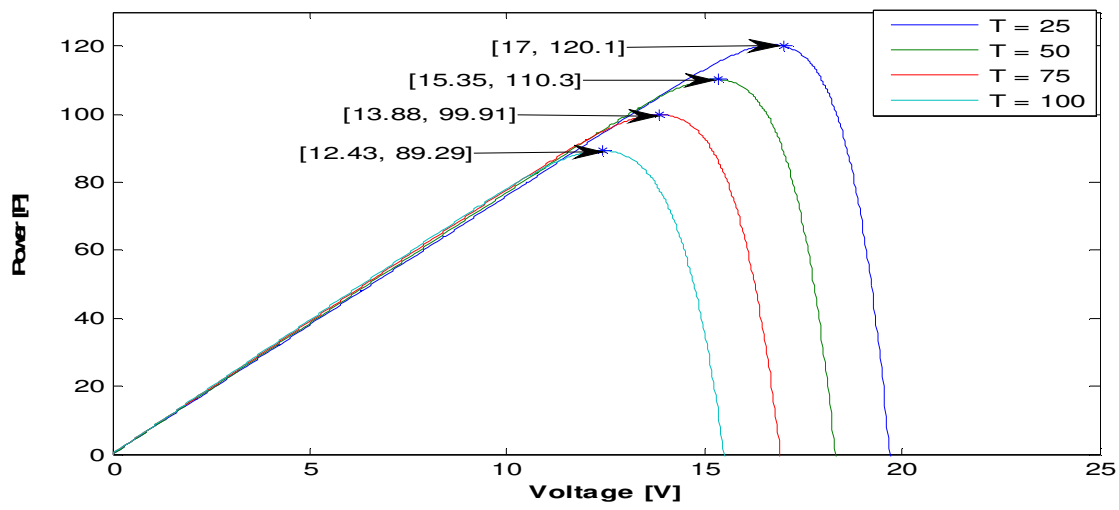

Figure 8.bP-V characteristics of two diode for varying temperature T (C)

\section{CONCLUSIONS}

The main objective of this paper was to show the difference in I-V and P-V characteristics of single diode and two diode equivalent circuits, which were produced after implementation of these models in matlab through programming using a flowchart formulated as shown in Fig. 4. BP Solarex MSX-120 polycrystalline PV module datasheet has been used for verification of matlab program. Hence, after observing all characteristic curves by varying solar irradiance $G$ and temperature $\mathrm{T}$ and potting $\mathrm{I}-\mathrm{V}$ and $\mathrm{P}-\mathrm{V}$ curves, it can be concluded that two diode model gives more precise characteristics close to practical photovoltaic solar cell as compared to single diode model characteristics. But in two diode model implementation we face more complex equation and two more unkown parameters, also number of iterations increases accordingly in forming solar cell characteristics. So, choosing a electrical equivalent model between these two can is based on area in which we would like to realise for study of solar cell characteristics. Like for power system planning purpose, single diode model is better as it will save time. Whlie for study of solar cell characteristics at critical points two diode is more preferable.

\section{REFERENCES}

[1] Saloux Etienne, Teyssedou Alberto, SorinMikhaïl. "Explicit model of photovoltaic panels to determine voltages and currents at the maximum power point”. Sol Energy 2011;85(5), pp. 713-22.

[2] IshaqueKashif, Salam Zainal, Taheri Hamed. "Simple, fast and accurate two diode model for photovoltaic modules”. Sol Energy Mater Sol Cells 2011;95(2), pp. 586-94.

[3] Tsai Huan-Liang. "Insolation-oriented model of photovoltaic module using Matlab/simulink". Sol Energy 2010;84(7), pp.1318-26.

[4] Gow, J.A.; Manning, C.D., "Development of a photovoltaic array model for use in power-electronics simulation studies," Electric Power Applications, IEE Proceedings - , vol.146, no.2, pp.193-200, Mar 1999 doi: 10.1049/ip-epa:19990116.

[5] Yetayew, T.T.; Jyothsna, T.R., "Improved single-diode modeling approach for photovoltaic modules using data sheet," India Conference (INDICON), 2013 Annual IEEE, vol., no., pp.1-6, 13-15 Dec. 2013 doi: 10.1109/INDCON.2013.6726092.

[6] Besheer, A.H.; Abdelaziz, A.Y., "A comparative analysis for different kinds of single diode model photovoltaic module," Innovative Smart Grid Technologies - Asia (ISGT Asia), 2014 IEEE , vol., no., pp.41-46, 20-23 May 2014.

[7] Hyeonah Park; Hyosung Kim, "PV cell modeling on single-diode equivalent circuit," Industrial Electronics Society, IECON 2013 - 39th Annual Conference of the IEEE, vol., no., pp.1845-1849, 10-13 Nov. 2013. 
Electrical \& Computer Engineering: An International Journal (ECIJ) Volume 4, Number 2, June 2015

[8] Suthar, M.; Singh, G.K.; Saini, R.P., "Comparison of mathematical models of photo-voltaic (PV) module and effect of various parameters on its performance," Energy Efficient Technologies for Sustainability (ICEETS), 2013 International Conference on, vol., no., pp.1354-1359, 10-12 April 2013.

[9] Filippo Attivissimo, Francesco Adamo, Alessio Carullo, Anna Maria Lucia Lanzolla, Filippo Spertino, Alberto Vallan. "On the performance of the double diode model in estimating the MPP for different photovoltaic technologies”. Measurement 46 (2013) pp.3549-3559.

[10] BP SOLAREX MSX-120W PV module datasheet.www.altestore.com

\section{AUTHORS}

VivekTamrakar $^{1}$ Completed B.E. from SSCET Bhilai, Chhattisgarh in 2012.Iam currently pursuing M.Tech from MANIT Bhopal, Madhya Pradesh.

Dr. S.C. Gutpa ${ }^{2}$ received $\mathrm{PhD}$ degree in Electrical engineering from RGPV, Bhopal (2010), Currently he is Associate professor. His research interest includes Renewable Energy System and Power System Analysis

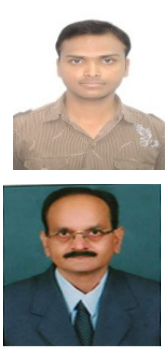

Yashwant Sawle ${ }^{3}$ received BE degree in Electrical engineering from SATI VidishaMP, (2006), and M.Tech degree in Power System (2010) from MANIT, Bhopal. At the moment he is Ph.D. scholar at MANIT, Bhopal, India.

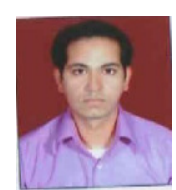

